\title{
ТЕОРЕТИЧЕСКИЕ И МЕТОДИЧЕСКИЕ ОСНОВЫ ПЕРЕХОДА БЕЛОРУССКИХ ВУЗОВ К МОДЕЛИ «УНИВЕРСИТЕТ 3.0»
}

\begin{abstract}
И.В. Марахина*
Обосновывается актуальность для белорусских вузов перехода к модели «Университет $3.0 »$, что является важным направлением в развитии системы образования Республики Беларусь. Выявлены сущностные особенности этой модели и основные направления преобразования вузов в соответствии с ней. Проанализирован комплекс мер по совершенствованию деятельности белорусских вузов на основе модели «Университет 3.0» и предложены рекомендации по его расширению.
\end{abstract}

Ключевые слова: университет 3.0, предпринимательский университет, модель, Беларусь.

JEL-классификация: I23, I25.

DOI: $10.46782 / 1818-4510-2021-1-140-155$

Материал поступил 4.12.2020 2.

В соответствии с Концептуальными подходами к развитию системы образования Республики Беларусь до 2020 года и на перспективу до 2030 г. ${ }^{1}$ внедрение модели «Университет 3.0» определено в качестве составляющей механизма достижения поставленных задач в сфере высшего образования до 2020 г. Такая модель определяет три ключевых направления деятельности вуза (преподавание, научные исследования, предпринимательство), обеспечивающих подготовку предпринимателей-инноваторов, производство инновационных идей и продуктов для разных отраслей экономики, коммерциализацию результатов труда сотрудников и студентов, развитие науки, формирование инновационной экосистемы и др. (Etzkowitz, Zhou, 2018; Андрюшкевич, Денисова, 2014 и др. $)^{2}$. Представ-

1 URL: https://edu.gov.by/sistema-obrazovaniya/ glavnoe-upravlenie-professionalnogo-obrazovaniya/prof-obr/ respublikanskyi-sovet-direktorov-uchrezhdeniy-professionalnotekhnicheskogo-i-srednego-spetsialnogo-/

${ }^{2}$ Марахина И.В. 2019. Коммерциализация результатов научно-технической деятельности в условиях перехода вузов к модели «Университет 3.0». Высшая школа: проблемы и перспективы: материалы XIV Международной научно-методической конференции. Минск: Академия управления при Президенте Республики Беларусь. С. 91-93. ленное в статье исследование направлено на обоснование актуальности, дополнение теоретических и методических основ и выявление для белорусских вузов путей перехода к модели «Университет $3.0 »$.

\section{Теоретические основы концепции «Университет 3.0»}

Понятие «предпринимательский университет» («Entrepreneurial Universities») было введено Б. Кларком, в дальнейшем стали появляться его альтернативные названия «Университет 3.0», университет третьего поколения. Однако единого определения до сих пор не выработано: это связано с тем, что концепция «Университет $3.0 »$ еще формируется и в соответствии с новыми теоретическими и практическими достижениями продолжает уточняться и развиваться.

Считается, что ключевой особенностью модели «Университет 3.0» является включение новой функции - предпринимательства. Однако такая функция - это не простое дополнение, но и преобразование остальных двух - образовательной и научной, и в целом подходов к управлению университетом.

* Марахина Инна Викторовна (ina_marahina@tut.by), кандидат экономических наук, доцент, Белорусский государственный университет информатики и радиоэлектроники (г. Минск, Беларусь). 
Теоретические и методические основы перехода белорусских вузов к модели «Университет 3.0»

Таким образом, к основным сущностным особенностям модели «Университет 3.0» можно отнести следующие.

1. Появление новой функиии - предпринимательства, определяющего коммерщиализащию новых знаний за счет управления интеллектуальной собственностью, создания стартапов, спин-офф организаций. Как отмечают H. Etzkowitz, Ch. Zhou (2018), предпринимательский университет «переводит результаты академических знаний в экономическую деятельность». При этом к предпринимательской деятельности привлекается максимальное число как сотрудников, так и обучающихся университета. Так, А. Карпов (2017) подчеркивает, что важнейшей особенностью инновационного и предпринимательского университета является «расширение компетенций студентов в социально-экономической сфере и включение их в непосредственную экономическую деятельность».

Как отмечает Й. Виссема (2016), если для университетов второго поколения коммерциализация знаний была личным делом преподавателей, в лучшем случае интересной побочной работой, которая разрешалась до тех пор, пока она не вступала в конфликт с основной научно-педагогической деятельностью, то для университетов третьего поколения, наоборот, коммерциализация является третьим, основным видом деятельности, нормативно им предписанным. «Университеты третьего поколения несут облзательство извлекать прибыль из создаваемых ими знаний» (Там же).

Наряду с продажей объектов интеллектуальной собственности, выполнением работ по заказу Университет 3.0 активно реализует такую форму коммерциализации результатов интеллектуальной деятельности, как создание стартапов, спин-офф организащий. H. Etzkowitz и Ch. Zhou (2018) предполагают, что благодаря особым способностям в интеграции организационного обучения, групповых исследований и коллективного предпринимательства университет будет источником для новых фирм. Он берет на себя роль промышленности, стимулируя развитие новых фирм на основе исследований, вводя «капитализацию знаний» в качестве академической цели.
2. Изменение подходов к осуществлению обучения, подготовка предпринимателей и инноваторов.

2.1. Предпринимательский подход к осуществлению обучения, направленный на повышение конкурентоспособности университета на международном рынке. Й. Виссема (2016) указывает на космополитичность университетов, их работу в международном контексте, преподавание только на английском языке. При этом массовость обучения корректируется, согласно Й. Виссеме, «двунаправленностью» (two track): университеты третьего поколения создают особые условия для ведущих ученых, наиболее талантливых студентов и преподавателей в рамках части своих проектов, одновременно реализовывая программы массового высшего образования.

2.2. Активизация теоретической и практической подготовки обучающихся к предпринимательской деятельности, в том числе путем создания ими жизнеспособных проектов и спин-офф компаний в течение процесса обучения. Как пишет М.Д. Щелкунов (2017), для Университетов 3.0 характерны объединение преподавания с решением прикладных задач, более широкое использование наставничества со стороны компаний, переход от проблемы информационного обеспечения академической постановки задачи к умению решать исследовательские задачи на имеющемся информационном уровне. Как отмечает А. Карпов (2017), роль Университета 3.0 состоит «в воспитании специалистов инновационного типа, которые обладают компетенциями для перехода от исследований к разработкам с их последующей коммерциализацией».

3. Изменение подходов к осуществлению научной деятельности. Повышение конкурентоспособности в рамках предпринимательства требует роста эффективности проведения научных работ, вовлечения сотрудников и обучающихся в научный процесс, учета изменения характера научных исследований. При этом большое внимание уделяется востребованности и ориентированности на практическое использование создаваемых знаний. Как пишет Щелкунов (2017), Университет 3.0 ориентирован на генерацию знаний, «которые работают, в 
отличие от знаний, которые отвечают академическим стандартам».

4. Изменение принципов работь университета в качестве предпринимательской единицы. Так, можно выделить следующие приоритеты в работе Университета 3.0.

4.1. Конкурентоспособность и экономическая эффективность университета, обеспечение его для этого лучшими ресурсами (в первую очередь интеллектуальными). Й. Виссема (2016) отмечает, что университеты третьего поколения соперничают на глобальных рынках «за лучших преподавателей и студентов и за исследовательские контракты с компаниями».

4.2. Предпринимательский риск и инновационность. Как отмечает Б. Кларк (2011), важной чертой в таких университетах является «принятие рисков при освоении новых практик, результат которых неясен. Предпринимательский университет активно стремится к инновациям в своей работе. Он хочет существенно изменить характер деятельности организации для того, чтобы оказаться в будущем в более благоприятном положении».

4.3. Самостоятельность и экономическая независимость. Й. Виссема (2016) пишет, что Университеты 3.0 будут «меньше зависеть от государственного регулирования и в конечном счете могут полностью выйти из-под патронажа государства, если прямое финансирование с его стороны будет замещено косвенным финансированием и если государство прекратит оказывать влияние на содержание учебных планов и требования к получению дипломов о высшем образовании. Это тем не менее не повлечет за собой восстановления «академической свободы», поскольку исследовательские гранты будут по-прежнему выдаваться на условиях, сформулированных с учетом государственной политики в отношении университетов». На то, что предпринимательские университеты стремятся стать «важными самостоятельными игроками», указывал и Б. Кларк (2011).

4.4. Участие Университета 3.0, согласно Й. Виссеме (2016), в создании конкретных ценностей для общества (в этом заключается третья цель его существования). Таким образом интеллектуальная деятель- ность как в самом университете, как и в спин-офф организациях обеспечивает создание материальных и нематериальных благ.

Выделенные сущностные особенности модели «Университет 3.0» обуславливают следующие ее преимущества:

повышение конкурентоспособности и экономической эффективности работы учреждений. Рост экспорта образовательных и научно-исследовательских услуг;

повышение возможностей для стимулирования преподавателей и студентов, привлечения лучших из них, рост мотивированности и доходов преподавателей;

активизация инновационной деятельности, коммерциализация результатов труда, создание новых востребованных продуктов, рост занятости и снижение безработицы;

создание точек роста предпринимательства;

подготовка практико-ориентированных специалистов, предпринимателей и инноваторов;

высокий уровень и востребованность научных исследований, развитие науки в целом.

\section{Предпосылки перехода к модели «Университет 3.0»}

Анализ ряда научных работ показал, что переход к модели «Университет 3.0»это ответ на вызовы времени, который позволит университетам эффективно развиваться на конкурентном глобальном рынке, выступать активным элементом национальной инновационной системы и общества знаний. Среди ключевых вызовов времени, обуславливающих такой переход, следует отметить следующие.

Глобализачия, рост мобильности населения, определяющие выход все большего числа университетов на международный рынок. Это приводит к росту конкуренции за лучших студентов и сотрудников, за наиболее привлекательные научно-исследовательские контракты как между университетами, так и со стороны вновь созданных вне университетов специализированных высококлассных научно-исследовательских организаций (Виссема, 2016). 
Теоретические и методические основы перехода белорусских вузов к модели «Университет 3.0»

Увеличение спроса на образование, его массовизащия, определяемые политикой всеобщего охвата высшим образованием, развитием обучения в течение жизни, ростом требований к повышению квалификации (Виссема, 2016; Кларк, 2011). Й. Виссема отмечает массовый приток студентов в вузы, что вызывает проблемы с обеспечением качества образования и невозможность управлять университетами традиционным способом.

Смещение требований к выпускникам в сторону таких качеств, как инновационность и практикоориентированность, самозанятость, гибкость и предприимчивость.

Изменение характеристик научных исследований, в том числе, согласно Й. Виссема (2016):

возросшая стоимость передовых научных исследований;

повышение роли междисциплинарных исследований, которые формируют конфликт с традиционной организацией университета на основе факультетов и требуют включения в рабочие группы специалистов из различных сфер деятельности;

расширение возможностей сотрудничества с компаниями в качестве их внешних подрядчиков при повышении открытости корпоративных исследований. Так, высокотехнологичные компании из желания сократить внутренние расходы на фундаментальные исследования стали отдавать их внешним подрядчикам.

Экономоцентризм (Щелкунов, 2017) в качестве основы общественных отношений, который «нацелен на тотальный товарноденежный характер обмена продуктами деятельности, платность всех товаров и услуг, коммодификацию нематериальных продуктов... Университет, будучи вовлеченным в экономоцентристские тренды, трансформируется из классического социального института в экономического субъекта, занимающегося производством научно-образовательных услуг. Маркерами этой трансформации являются коммерческий характер обучения, использование экономических критериев эффективности вузов».

Рост технологического предпринимательства в вузовской среде, вдохновленного успехами ИТ-компаний, рожденных в универси- тетах США (Виссема, 2016). Согласно концепции «Тройной спирали» (Etzkowitz, Zhou, 2018), «университеты и правительства действуют как предприниматели, демонстрируя, что инновации и предпринимательство не ограничиваются бизнесом».

Рост иенности интеллектуальных ресурсов при переходе к обществу знаний, где университеты, являясь одним из ключевых производителей таких ресурсов, должны получать значительный доход. «При переходе к новой экономике, в которой знание становится главным источником конкурентных преимуществ и двигателем развития экономики, возникает проблема: как долго будет сохраняться ситуация, когда обладатели финансового капитала получают львиную долю прибыли, порожденной применением знаний, к генерации которых они не имеют непосредственного отношения? До каких пор университетские преподаватели, генерирующие и распространяющие знание, будут получать вознаграждение, существенно меньшее, чем их ученики, применяющие это знание в бизнесе? Столь ли очевидно, что все знание, рожденное в университете, должно быть общественным благом?» (Константинов, Филонович, 2007).

Рост значимости университетов как институтов общества знаний, инноващионной экономики. H. Etzkowitz, Ch. Zho (2018) пишут, что предпринимательские университеты играют значительную роль в «Тройной спирали» - «ключу к экономическому росту и социальному развитию, основанному на знаниях» - через передачу технологий, создание новых фирм и развитие регионов. Й. Виссема (2016) указывает на требование государства к университетам «играть активную роль в обеспечении высокотехнологической составляющей роста экономики знаний».

Разгосударствление социальных институтов. «Чем дальше, тем больше обнаруживается неэффективность тотально государственного управления и централизованного ресурсного обеспечения учреждений высшего образования: обреченность государственных вузов на финансирование по остаточному принципу, нарастающая неспособность государства обновлять и эффективно поддерживать учебно-лаборатор- 
ную базу образования в условиях инновационных изменений, обеспечивать материально-финансовыми ресурсами развитие вузовской науки. Разгосударствление высшей школы становится ведущим трендом» (Щелкунов, 2017).

\section{Методические основы перехода к модели «Университет 3.0»}

Анализ научных работ и представленные выше теоретические положения позволяют выделить направления преобразования вузов в соответствии с моделью «Университет 3.0». Следует отметить, что такие направления затрагивают всю работу организации и требуют формирования новых целей, структур и их среды (организационной культуры), а также подходов к взаимодействию с окружающей средой и включают следующие.

1. Изменение целей, задач и стратегий университетов. Так, на первое место в модели «Университет 3.0» выходят: формирование эффективного предпринимательского поведения, повышение инновационной активности и подготовка предпринимателей, коммерциализация результатов научного труда сотрудников. При этом для их реализации университеты активно начинают использовать инновационные стратегии, стратегии коммерциализации.

2.Переход к новой организащионной структуре, обеспечивающей активизацию предпринимательства, научной, инновационной деятельности. Для модели «Университет 3.0» ряд ученых предлагают сетевые структуры (Виссема, 2016; Карпов, 2017; Кларк, 2011), ориентированные на внешнее взаимодействие, реализацию интеллектуального потенциала сотрудников, адаптивность, междисциплинарность, активизацию предпринимательства. А. Карпов (2017) отмечает, что формирование сетевой модели университета обусловлено особенностями общества знаний, развивающегося как общество взаимосвязанных организаций, которые либо институционально интегрируются в рамках общей «административной платформы», либо взаимодействуют как сложные сетевые партнерства. К основным направлениям трансформации организационной структуры при переходе к модели
«Университет 3.0» можно отнести следующие.

2.1. Модернизация системы управления вузом. Для этого Б. Кларк (2011) предлагает создание центра управления, который позволяет более быстро и гибко реагировать на растущие и меняющиеся запросы, более организованно перестраивать свои программные задачи. Такое ядро должно включать центральные управленческие группы и университетские отделения. Оно оперативно согласовывает новые управленческие ценности с традиционными академическими.

2.2. Расширение внешних связей с учетом развития междисциплинарного подхода, в том числе:

рост единиц, которые с большей готовностью, чем традиционные университетские отделения, выходят за старые университетские границы и устанавливают связи с внешними организациями и группами (Кларк, 2011);

сотрудничество с бизнесом, создание совместных лабораторий, проведение «совместных исследований», в ходе которых команда исследователей из промышленной компании трудится бок о бок с университетскими учеными, что часто сопровождается финансовым пожертвованием компании в пользу университета (Виссема, 2016).

2.3. Формирование инфраструктуры поддержки инновационной, научной и предпринимательской деятельности, в том числе бизнес-инкубаторов, центров трансфера технологий, технопарков и др. Так, Й. Виссема (2016) отмечает важность формирования в дополнение к университетским структурам, ведущим научно-исследовательскую и образовательную деятельность, «карусели ноухау» («хаба ноу-хау»³), которая включает в себя научно-исследовательские подразделения компаний, независимые (часто узкоспециализированные) научно-исследовательские институты, инфраструктуру для техностартеров, инвесторов и фирм, предоставляющих профессиональные услуги. Конкурентное преимущество университета зависит от того, на-

3 «Карусель ноу-хау», или «хаб ноу-хау», можно определить как «группу организаций внутри или вне университета, предпочтительно размещающихся на его территории, которые сотрудничают с университетом, его профессорами и исследовательскими группами, а также между собой» (Виссема, 2016). 
Теоретические и методические основы перехода белорусских вузов к модели «Университет 3.0»

сколько он сможет позиционировать себя как ядро хаба ноу-хау, как открытую сеть взаимодействия с другими исследователями, компаниями, государственными и негосударственными организациями. Й. Виссема также указывает на рост устойчивости такого хаба с увеличением числа его элементов.

2.4. Переход от факультетов к междисциплинарным центрам, институтам. Й. Виссема (2016) указывает, что «чрезвычайно важными структурными единицами университетов третьего поколения становятся институты - трансдисциплинарные подразделения, специализирующиеся на конкретных областях исследований. Университетские институты по своей природе являются предпринимательскими организациями; они сами нанимают сотрудников и подотчетны напрямую правлению вуза». По мнению ученого, по мере перехода сотрудников в университетские институты факультеты, отвечающие прежде всего за образовательные программы, утрачивают размеры и влияние и в конечном счете могут исчезнуть. Согласно Б. Кларку (2011), междисциплинарные проектно-ориентированные научно-исследовательские центры наряду с отделениями начинают играть все большую роль и занимаются решением проблем, которые не ограничиваются рамками отдельных дисциплин. «Они приносят в университет проектный подход представителей внешней среды, которые пытаются решать серьезные практические проблемы, имеющие большое значение для экономического и социального развития. Эти центры обладают определенной гибкостью, так как их сравнительно легко создавать и распускать. Преодолевая старые границы, они выступают в роли посредников между отделениями и внешним миром». При этом университетские отделения или факультеты, основанные на дисциплинарном разделении, сохраняют свою значимость: «их компетентность в конкретных дисциплинах важна и слишком ценна, чтобы ею можно было пренебречь, и они достаточно сильны, чтобы защитить свои владения».

2.5. Создание междисциплинарных команд. На важность командного подхода указывает Б. Кларк (2011): «скорее, трансформация происходит тогда, когда в базовых единицах университета и в нем самом многие люди объединяются для того, чтобы со временем путем организованной инициативы изменить устройство и ориентацию института. Коллективная предпринимательская деятельность на этом уровне составляет основу феномена трансформации. Действующие «сверху» национальные и государственные системы высшего образования не слишком подходят для существенных изменений; действующие «снизу» отдельные преподаватели и администраторы ограничены в своих возможностях. Но группы преподавателей и администраторов (а иногда и студентов!), большие и не очень, общеуниверситетские и факультетские, способны создать новые структуры, процессы и интерпретации, позволяющие университету склониться в сторону адаптивных изменений». Ученый отмечает, что такой командный формат работы позволяет осуществлять преобразования на основе университетских ценностей, помогает приобрести ресурсы и инфраструктуру и не выводит университет «за границы академической легитимности».

Й. Виссема (2016) подчеркивает роль междисциплинароного подхода и указывает, что «для трансдисциплинарных исследований необходимо объединение усилий представителей нескольких факультетов».

3. Формирование предпринимательской культуры, обеспечиваюшей поддержку реализации целей Университета 3.0. В работе Б. Кларка (2011) речь идет о культуре деятельности, ориентированной на изменения, вырастающей из совокупности устойчивых представлений и практик.

4. Развитие системы мотивачии, в том числе мотивачии инновачионной деятельности, предпринимательства, научной деятельности. Она должна быть ориентирована на потенциальных и реальных участников научной и предпринимательской деятельности, инновационного процесса, которые прямо или косвенно (например, консультанты) в нем задействованы. Важно введение системы критериев оценки и поощрений ${ }^{4}$.

\footnotetext{
${ }^{4}$ Марахина И.В. 2019. Коммерциализация результатов научно-технической деятельности в условиях перехода вузов к модели «Университет 3.0». Высшая школа: проблемы и перспективы: материалы XIV Международной научно-методической конференции. Минск: Академия управления при Президенте Республики Беларусь. С. 91-93.
} 
Дж. Лэнг 5 указывает, что у начинающего предпринимателя должно быть все необходимое для начала работы: 1) финансирование, широкополосный интернет, человеческие ресурсы, жидкий гелий - что угодно; 2) схемы обеспечения возврата займов, выгодные условия ипотечного кредитования, льготные периоды при возврате кредитов, инфраструктура для детей, круглосуточные магазины и т. п.; 3) налоговые льготы, обеспечиваемые работодателем или университетом, и здравая политика в отношении интеллектуальной собственности.

Й. Виссема (2016) указывает на следующий момент в мотивации: важно, чтобы университет оставлял большую часть интеллектуальной собственности ее создателям - преподавателям и студентам.

5. Активизащия научной деятельности и изменение подходов к ее осуществлению. Так, Й. Виссема (2016) говорит о необходимости ведущему университету третьего поколения самому брать на себя инициативу превращения в хаб, объединяющий различные организации, участвующие в создании и коммерциализации ноу-хау. «Такой центр может получить международное признание как флагман в создании знаний в конкретных научных областях; это центр, который не могут игнорировать ни один исследователь и ни одна компания, действующие в конкретной области знаний; это центр, в высшей мере привлекательный для студентов и профессоров».

6. Диверсификащия источников финансирования и доходов. Б. Кларк (2011) обращает внимание на такие важные источники, как:

гранты и контракты коммерческих компаний, органов власти и благотворительных фондов;

лицензионные отчисления за интеллектуальную собственность;

доходы от услуг, оказываемых на территории университета;

плата студентов за обучение;

пожертвования выпускников.

Ученый отмечает, что вышеназванные источники (за исключением первого - грантов и контрактов) особенно ценны, так как

${ }^{5}$ Lang J. 2003. Creating the climate for innovation. Handout, the University of Cambridge. См. (Виссема, 2016). позволяют получать дискреционные средства и предоставляют университетам ряд свобод и возможностей. Й. Виссема (2016) подчеркивает, что «процветание университетов третьего поколения в условиях жесткого государственного регулирования невозможно». Поэтому он предлагает передать средства государственного финансирования университетского образования независимым организациям-посредникам, т. е. заменить прямое финансирование финансированием через независимых посредников.

Особое внимание в функционировании Университетов 3.0 в работе А.В. Бондаря, П.А. Лиса, В.А. Слиж (2018) уделяется формированию фондов целевого капитала (эндаумент), создающихся за счет благотворительных пожертвований и позволяющих университету получать доходы от управления этим фондом в долгосрочной перспективе.

Следует отметить, что, демонстрируя предпринимательское поведение, университет стремится к коммерциализации всех своих сфер деятельности. Здесь на первый план выходят такие направления, как реализация прав на объекты интеллектуальной собственности, создание новых организаций, спонсорство, выполнение научно-инновационных работ по заказу. При этом продолжают совершенствоваться такие формы, как получение платы за образовательные услуги, выполнение научно-исследовательских работ.

7. Реализачия новых методов преподавания и массового образования. Среди преобразований образовательной функции необходимо отметить ориентацию на предпринимательство, практикоориентированность, новые дисциплины. Й. Виссема (2016) обращает внимание, что английский язык стал новым «lingua franca» в Университете 3.0.

Важным видится формирование понимания сущности и роли коммерциализации результатов научной и инновационной деятельности у всех потенциальных участников инновационного процесса - обучающихся и сотрудников вуза, а также передача им знаний и умений, которые необходимы для осуществления коммерциализации, в том числе в области: оценки рынка разрабатываемого продукта и потребностей потребителей, организации работы на рынке интеллектуальной собственности, защи- 
Теоретические и методические основы перехода белорусских вузов к модели «Университет 3.0»

ты объектов интеллектуальной собственности, инициации и управления инновационными процессами, поиска инвесторов и выбора модели финансирования и т. д. Для реализации данного направления необходимо оптимизировать учебные планы и развивать образовательный процесс, в том числе вводить с первого курса дисциплины в области предпринимательства, коммерциализации, а также проводить образовательные курсы для сотрудников ${ }^{6}$.

\section{Задачи перехода к модели «Уииерситет 3.0» в Республике Беларусь}

Следует отметить, что наряду с указанными выше глобальными вызовами перед вузами Республики Беларусь стоит ряд других задач, обусловленных спецификой их внешней и внутренней среды и определяющих необходимость перехода вузов к модели «Университет $3.0 »$.

1. Повышение конкурентоспособности вузов в условиях сужающегося внутреннего рынка.

Статистические данные свидетельствуют о снижении численности студентов, обучающихся в белорусских вузах (табл. 1).

При этом достаточно большое число студентов обучается в зарубежных вузах, что еще больше сужает внутренний рынок. Так, по состоянию на 31 декабря 2018 г. в польских университетах училось 7314 студентов из Беларуси, в том числе 3071 первого года обучения 7 . Согласно данным

${ }^{6}$ Марахина И.В. 2019. Коммерциализация результатов научно-технической деятельности в условиях перехода вузов к модели «Университет $3.0 »$. Высшая школа: проблемы и перспективы: материалы XIV Международной научно-методической конференции. Минск: Академия управления при Президенте Республики Беларусь. С. 91-93.

7 URL: https://stat.gov.pl/obszary-tematyczne/edukacja/ edukacja/szkoly-wyzsze-i-ich-finanse-w-2018-roku,2,15.html

за 2019 г., в российские вузы (бакалавриат и специалитет) зачислили 2564 студента из Беларуси, общая численность обучающихся по программам бакалавриата и специалитета составила 9184. Кроме того, число обучающихся в соответствии с международными договорами Российской Федерации, с федеральными законами или установленной Правительством Российской Федерации квотой по программам бакалавриата и специалитета, составило 612 чел. (зачислено - 211 чел.) ${ }^{8}$. Такая ситуация указывает на необходимость повышения конкурентоспособности отечественных вузов, их привлекательности для белорусов.

Одновременно следует отметить постепенный рост числа студентов и магистрантов, приезжающих в белорусские вузы изза рубежа (табл. 2). Привлекает внимание сильная зависимость экспорта образовательных услуг от сотрудничества с Туркменистаном: доля студентов и магистрантов из этой страны составляет более $50 \%$.

О недостаточном уровне конкурентоспособности белорусских вузов на международном рынке свидетельствует включение только нескольких из них в известные рейтинги. Так, в международном рейтинге SCIMAGO 2020 представлены только три белорусских вуза: БГУ, БНТУ и БГУИР (всего проранжировано 3897 учреждений) ${ }^{9}$. A в рейтинге Best Global Universities 2021 (ежегодном рейтинге лучших мировых университетов, ранжирующем 1500 учебных заведений), только один белорусский БГУ ${ }^{10}$.

\footnotetext{
${ }^{8}$ URL: https://minobrnauki.gov.ru/action/stat/highed/

9 CImago Institutions Rankings, 2020. URL: https:// www.scimagoir.com/rankings.php?sector=Higher\%20educ

${ }^{10}$ URL: https://www.usnews.com/education/best-globaluniversities/europe
}

Таблица 1

Численность, прием студентов и магистрантов в учреждения высшего образования Республики Беларусь, тыс. чел.

\begin{tabular}{|l|r|r|r|r|r|r|r|r|}
\hline \multicolumn{1}{|c|}{ Показатель } & \multicolumn{1}{|c|}{2012} & \multicolumn{1}{|c|}{2013} & \multicolumn{1}{|c|}{2014} & \multicolumn{1}{c|}{2015} & \multicolumn{1}{c|}{2016} & \multicolumn{1}{c|}{2017} & \multicolumn{1}{c|}{2018} & 2019 \\
\hline Принято студентов & 88,1 & 68,7 & 63,4 & 63,1 & 62,7 & 61,8 & 58,9 & 60,0 \\
\hline Численность студентов & 428,4 & 395,3 & 362,9 & 336,4 & 313,2 & 284,3 & 268,1 & 260,9 \\
\hline Принято в магистратуру & 4,5 & 5,2 & 6,0 & 6,8 & 7,7 & 10,4 & 8,2 & 6,3 \\
\hline Численность магистрантов & 6,1 & 7,6 & 8,9 & 10,2 & 11,8 & 14,9 & 14,7 & 11,9 \\
\hline
\end{tabular}

Источник. Статистический ежегодник Республики Беларусь, 2020. Минск: Национальный статистический комитет Республики Беларусь. 
Численность студентов и магистрантов - иностранных граждан, обучающихся в учреждениях высшего образования Республики Беларусь (на начало учебного года)

\begin{tabular}{|c|c|c|c|c|c|c|c|c|}
\hline \multirow{2}{*}{ Показатель } & \multicolumn{8}{|c|}{ Учебный год } \\
\hline & $2012 / 13$ & $2013 / 14$ & $2014 / 15$ & $2015 / 16$ & $2016 / 17$ & $2017 / 18$ & $2018 / 19$ & $2019 / 20$ \\
\hline Всего, чел. & 12512 & 13863 & 14796 & 15356 & 15971 & 15570 & 16654 & 19745 \\
\hline $\begin{array}{l}\text { Из них из Туркме- } \\
\text { нистана, чел. }\end{array}$ & 6535 & 7908 & 8408 & 8279 & 7982 & 7219 & 7965 & 10056 \\
\hline $\begin{array}{l}\text { Доля студентов из } \\
\text { Туркменистана в общей } \\
\text { численности студентов } \\
\text { и магистрантов - } \\
\text { иностранных граждан, \% }\end{array}$ & 52,2 & 57,0 & 56,8 & 53,9 & 50,0 & 46,4 & 47,8 & 50,9 \\
\hline
\end{tabular}

Источник. Статистический ежегодник Республики Беларусь, 2020. Минск: Национальный статистический комитет Республики Беларусь.

2. Активизащия инноващионной деятельности в стране. В Республике Беларусь взят курс на переход к инновационной экономике, однако показатели инновационной активности недостаточно высоки (табл. 3).

Учреждения образования, обеспечивающие подготовку, переподготовку и повышение квалификации кадров в сфере инновационной деятельности, выступают в качестве компонента Национальной инновационной системы $^{11}$, и их деятельность должна соответствовать такому направлению государственной инновационной политики Республики Беларусь на 2016-2020 годы ${ }^{12}$, как кадровое обеспечение инновационного развития национальной экономики. Для его реализации определены следующие задачи ${ }^{13}$ : повышение качества подготовки специалистов для обеспечения инновационного развития отраслей национальной экономики, в первую очередь ее высокотехнологичных секторов; укрепление интеграции между производством,

11 URL: http://www.gknt.gov.by/deyatelnost/innova tsionnaya-politika/natsionalnaya_innovatsionnaya_sistema/

12 URL: http://www.gknt.gov.by/deyatelnost/ innovatsionnaya-politika/gpir/

13 URL: http://www.gknt.gov.by/deyatelnost/innova tsionnaya-politika/gpir/ наукой и системой профессионального и послевузовского образования; повышение престижа научной и инновационной деятельности; обеспечение притока талантливой молодежи в инновационную сферу путем создания условий финансовой поддержки реализации проектов от идеи до внедрения разработок. Таким образом, важным является активное вовлечение университетов в инновационный процесс.

В то же время для инновационного развития страны необходимо усиление работы университетов в области производства и коммерциализации инновационных продуктов, знаний.

Эффективнье сохранение, развитие $и$ реализачия человеческого капитала в вузах. В вузах сконцентрирован значительный человеческий капитал ${ }^{14}$, в то же время он реализуется в первую очередь в области образования. Так, отмечается, что большинство (более 62\%) работников с ученой сте-

14 Марахина И.В. 2019. Коммерциализация результатов научно-технической деятельности в условиях перехода вузов к модели «Университет $3.0 »$. Высшая школа: проблемь и перспективы: материалы XIV Международной научно-методической конференции. Минск: Академия управления при Президенте Республики Беларусь. С. 91-93.

Таблица 3

Показатели инновационной активности белорусских организаций

\begin{tabular}{|l|c|c|c|c|c|}
\hline \multicolumn{1}{|c|}{ Показатель } & 2015 & 2016 & 2017 & 2018 & 2019 \\
\hline $\begin{array}{l}\text { Удельный вес инновационно активных организаций в общем } \\
\text { числе обследованных организаций промышленности, \% }\end{array}$ & 19,6 & 20,4 & 21,0 & 23,3 & 24,5 \\
\hline $\begin{array}{l}\text { Удельный вес отгруженной инновационной продукции } \\
\text { в общем объеме отгруженной продукции организаций } \\
\text { промышленности, \% }\end{array}$ & & & & & \\
\hline
\end{tabular}

Источник. Наука и инновационная деятельность в Республике Беларусь, 2020. Минск: Национальный статистический комитет Республики Беларусь. 
Теоретические и методические основы перехода белорусских вузов к модели «Университет 3.0»

пенью предпочитает в качестве основной занятости преподавательскую деятельность в учреждениях высшего образования ${ }^{15}$. Поэтому важной является реализация человеческого капитала, сконцентрированного в вузах, также и в научной области, и в предпринимательской деятельности.

В Республике Беларусь отмечается необходимость активизации научной деятельности, на что указывает ряд показателей развития науки (табл. 4): критически низкий показатель наукоемкости ВВП, значение которого за последние 5 лет не превысило 0,60\%, снижение показателей патентной и изобретательской активности.

В то же время доля сектора высшего образования в научной работе недостаточно высокая, о чем свидетельствуют такие показатели, как внутренние затраты на научные исследования и разработки; персонал, занятый научными исследованиями и разработками; зарегистрированные НИОКР (табл. 4, 5).

15 О состоянии и перспективах развития науки в Республике Беларусь по итогам 2018 года: аналитический доклад. 2019. Минск: ГУ «БелИСА».
Кроме того, из 51 вуза в международный рейтинг SCIMAGO 2020 научно-исследовательских организаций вошло только 3 белорусских вуза - БГУ, БНТУ и БГУИР 16 (из 7026 проранжированных).

Не менее важной видится реализация интеллектуального капитала обучающихся и работников вузов в форме активизации предпринимательства. Необходимо обеспечение в вузах роста числа стартапов, спинофф и малых инновационных организаций, активизации лицензионной деятельности и получения доходов от продажи объектов интеллектуальной собственности. Следует отслеживать статистику по такому виду результативности университетов.

Наряду с реализацией человеческого капитала в вузах важно его сохранение и развитие. Анализ статистических данных показывает снижение численности преподавателей. Так, если на начало 2012/13 учебного года численность профессорско-преподавательского состава (основной персо-

${ }^{16}$ URL: https://www.scimagoir.com

Таблица 4

Показатели развития науки в Республике Беларусь

\begin{tabular}{|l|c|c|c|c|c|}
\hline \multicolumn{1}{|c|}{ Показатель } & 2015 & 2016 & 2017 & 2018 & 2019 \\
\hline $\begin{array}{l}\text { Расходы на научные исследования и опытно - } \\
\text { конструкторские разработки, \% к ВВП }\end{array}$ & 0,50 & 0,50 & 0,58 & 0,60 & 0,59 \\
\hline Выдано патентов на изобретения, ед. & 902 & 941 & 850 & 625 & 461 \\
\hline Действует патентов, ед. & 2858 & 2735 & 2414 & 2135 & 1813 \\
\hline $\begin{array}{l}\text { Доля сектора высшего образования } \\
\text { во внутренних затратах на научные } \\
\text { исследования и разработки, \% }\end{array}$ & 10,8 & 9,6 & 9,4 & 9,6 & 10,1 \\
\hline $\begin{array}{l}\text { Коэффициент изобретательской активности } \\
\text { (число отечественных патентных заявок на } \\
\text { изобретения, поданных в Беларуси, в расчете } \\
\text { на 10 000 чел. населения) }\end{array}$ & 0,6 & 0,5 & 0,5 & 0,5 & 0,4 \\
\hline $\begin{array}{l}\text { Персонал, занятый научными исследованиями } \\
\text { и разработками, чел. }\end{array}$ & 26153 & 25942 & 26483 & 27411 & 27735 \\
\hline \multicolumn{1}{|l}{ Из них сектор высшего образования, чел. } & 2607 & 2810 & 2964 & 2923 & 2883 \\
\hline
\end{tabular}

Источник. Наука и инновационная деятельность в Республике Беларусь, 2020. Минск: Национальный статистический комитет Республики Беларусь.

Таблица 5

Зарегистрированные в 2018 г. НИОК(Т)Р по секторам в Республике Беларусь

\begin{tabular}{|l|c|c|c|}
\hline \multirow{2}{*}{$\begin{array}{c}\text { Сектор научной } \\
\text { деятельности }\end{array}$} & \multirow{2}{*}{ Количество работ } & \multicolumn{2}{|c|}{ Объем финансирования работ, тыс. руб. } \\
\cline { 3 - 4 } & & Всего & в том числе бюджетные средства \\
\hline Всего & 2064 & 306312,9 & 187148,7 \\
\hline Вузовский & 682 & 29314,0 & 19925,0 \\
\hline Доля вузовского сектора, \% & 33,0 & 9,6 & 10,6 \\
\hline
\end{tabular}

Источник. О состоянии и перспективах развития науки в Республике Беларусь по итогам 2018 года: аналитический доклад. 2019. Минск: ГУ «БелИСА». 
нал) составляла 24612 чел., из них имело ученую степень доктора наук 1346 чел., а кандидата наук - 9043 чел., то на начало $2019 / 20$ учебного года их численность упала до 19 943, 1308 и 8118 соответственно ${ }^{17}$.

3. Снижение зависимости вузов от бюджетного финансирования и привлечение дополнительных средств для их развития.

А.В. Бондарь, П.А. Лис, В.А. Слиж (2018) указывают на высокую степень зависимости белорусской системы высшего образования от бюджетного финансирования, так как подавляющее большинство вузов республики являются государственными. Представленные в табл. 6 данные свидетельствуют, что около 65\% от внутренних затрат на научные исследования и разработки в секторе высшего образования приходятся на средства бюджета.

В то же время активизация образовательной, научной и предпринимательской деятельности требует дополнительных расходов и инвестиций. Однако динамика реальных расходов республиканского бюджета на образование характеризуется тенденцией к снижению (Там же).

\section{Переход белорусских вузов к модели «Университет 3.0»}

Начиная с 2018 г. концепция «Университет 3.0» реализовывается в семи белорусских вузах 18 : БГУ, БНТУ, БГУИР, БГЭУ, БРУ, ГрГУ, БГТУ - в рамках эксперимен-

${ }^{17}$ URL: https://www.belstat.gov.by/ofitsialnaya-statistika/ publications/izdania/public_compilation/index_18023/

${ }^{18} \mathrm{C} 1$ сентября $201 \overline{9}$ г. к эксперименту присоединился Полоцкий государственный университет. тального проекта «Совершенствование деятельности учреждений высшего образования на основе модели «Университет 3.0» (комплексное развитие научно-исследовательской, инновационной и предпринимательской инфраструктуры учреждения высшего образования в целях создания инновационной продукции и коммерциализации результатов интеллектуальной деятельности)» ${ }^{19}$ (далее Проекта). При его выполнении предусмотрено два направления действий ${ }^{20}$ :

- внесение изменений и дополнений в учебно-программную документацию образовательных программ высшего образования I ступени, направленных на системное взаимосвязанное изучение вопросов инновационной, изобретательской и предпринимательской деятельности (создание бизнес-среды), и в учебно-программную документацию образовательных программ высшего образования II ступени, направленных на реализацию стартапов в бизнесинкубаторах, командное выполнение высокотехнологичных проектов в рамках практико-ориентированного и научно-ориентированного обучения;

- реализация комплекса мер по созданию субъектов инновационной инфраструктуры (научно-технологических парков, центров трансфера технологий), отраслевых лабораторий, бизнес-инкубаторов, а также по повышению эффективности научно-исследовательской, инновационной деятельнос-

19 URL: http://bseu.by/russian/general/univer3/ description.htm

${ }_{20}$ URL: http://nihe.bsu.by/index.php/2opisanieeksperimentalnogo-proekta

Таблица 6

Внутренние затраты на научные исследования и разработки по источникам финансирования в секторе высшего образования (тыс. руб́., 2015 г. - млн руб.)

\begin{tabular}{|l|c|c|c|c|c|}
\hline \multicolumn{1}{|c|}{ Показатель } & 2015 & 2016 & 2017 & 2018 & 2019 \\
\hline $\begin{array}{l}\text { Объем финансирования внутренних затрат на научные } \\
\text { исследования и разработки }\end{array}$ & 485358 & 45643 & 57825 & 71027 & 78734 \\
\hline $\begin{array}{l}\text { Из них по источникам финансирования: } \\
\text { собственные средства }\end{array}$ & 4374 & 848 & 1293 & 3953 & 4287 \\
\hline средства бюджета & 294554 & 25245 & 35106 & 43801 & 51208 \\
\hline средства внебюджетных фондов & 4258 & 684 & 297 & 409 & 430 \\
\hline $\begin{array}{l}\text { средства иностранных инвесторов, включая } \\
\text { иностранные кредиты и займы }\end{array}$ & 57526 & 5073 & 6481 & 4835 & 4055 \\
\hline средства других организаций & 124460 & 13793 & 14537 & 18029 & 18746 \\
\hline
\end{tabular}

Источник. Наука и инновационная деятельность в Республике Беларусь, 2020. Национальный статистический комитет Республики Беларусь. Минск: Национальный статистический комитет Республики Беларусь. 
Теоретические и методические основы перехода белорусских вузов к модели «Университет 3.0»

ти, которые будут обеспечивать на завершающем этапе коммерческую реализацию инновационной продукции и (или) результатов интеллектуальной деятельности.

В соответствии с Проектом до 31.08.2020 г. предусмотрены меры, ориентированные в первую очередь на развитие образовательного процесса, в том числе ${ }^{21}$ :

разработка Дорожной карты преобразований;

первичное и ежегодное (для оценки эффективности мероприятий) проведение исследования состояния предпринимательского потенциала студентов;

внесение изменений и дополнений в учебно-программную документацию образовательных программ высшего образования I и II ступени или проектирование нового содержания образовательных программ I ступени высшего образования, а также образовательных программ повышения квалификации;

организация образовательного процесса по освоению нового содержания образовательных программ I и II ступени высшего образования;

внедрение в образовательный процесс новых технологий преподавания и обучения, изменение организации образовательного процесса в соответствии с новым проектом Кодекса об образовании.

Начиная с сентября 2020 г., наряду с продолжением освоения содержания образовательных программ, запланированы мероприятия, определяющие развитие инновационной инфраструктуры и организацию инновационной деятельности в университетах, принимающих участие в эксперименте, в том числе ${ }^{22}$ :

создание и развитие проектных команд студентов (молодых предпринимателей), которые ориентированы на участие в международном конкурсе Enactus;

реализация комплекса мер по созданию и развитию субъектов инновационной инфраструктуры, отраслевых лабораторий, стартап-школ; программ бизнес-акселерации, хакспейсов, бизнес-инкубаторов и др.;

21 URL: http://bseu.by/russian/general/univer3/ description.htm

${ }^{22}$ Там же. реализация комплекса мер по повышению эффективности научно-исследовательской, инновационной деятельности, которые будут обеспечивать на завершающем этапе коммерческую реализацию инновационной продукции и (или) результатов интеллектуальной деятельности;

создание республиканского Интернетпортала по обмену информацией между университетами и предприятиями: «наука бизнес».

Следует отметить, что анализ уровня реализации и эффективности описанных выше мер в рамках Проекта затрудняется отсутствием ежегодной и текущей сводной статистики о проделанной работе по данному вопросу. В то же время публикации в периодических и научных источниках, а также информация, представленная на сайтах ряда университетов - участников эксперимента, позволяет сделать вывод о выполнении в срок большинства мероприятий.

Так, в 2018 г. университеты разработали дорожные карты по совершенствованию образовательной, научной деятельности, подготовили пакет предложений по развитию инновационной инфраструктуры за счет средств Всемирного банка развития, в них открыты по I и II ступеням высшего образования инновационные специальности, разрабатывалось новое содержание образовательных программ²3. Эта работа была продолжена в 2019 г. Так, за 2019 г. в четыpex университетах открыта подготовка по трем и спроектированы две новые специальности инновационной, изобретательской и предпринимательской направленности. В образовательный процесс введены более 50 соответствующих учебных дисциплин. Пересмотрена методика образовательного процесса, используются новые технологии обучения. Планируется открытие новых специальностей на уровне дополнительного образования взрослых. Внедрены новые элементы образовательной среды для развития инновационного поведения обучающейся молодежи во внеучебное время ${ }^{24}$.

${ }^{23}$ URL: https://www.belstu.by/Portals/0/www-belta-byinterview-view-razvitie-universitetov-v-sovershenstvovanii-ihinnovatsionnoj-dejatelnosti-6666.pdf

${ }^{24}$ URL: https://www.belta.by/society/view/proektuniversitet-30-prizvan-sformirovat-u-studentov-interes-kkarjere-uchenogo-karpenko-376991-2020/ 
Кроме того, параллельно велась работа по реализации мероприятий, запланированных на текущий и последующие учебные годы и определяющих развитие инновационной инфраструктуры и активизацию инновационной деятельности в университете.

В 2018 г. инновационная инфраструктура вузов Министерства образования пополнилась 8 отраслевыми лабораториями для решения задач машиностроения, здравоохранения, финансовой и налоговой сферы. Таким образом, к началу 2019 г. в ее состав входили 17 отраслевых лабораторий, 6 научно-технологических парков и 2 центра трансфера технологий ${ }^{25}$. В 2019 г. в БГУИР на базе научно-образовательного инновационного центра СВЧ технологий и их метрологического обеспечения ${ }^{26}$, а в БГЭУ на базе кафедры экономики торговли и услуг факультета коммерции и туристической индустрии ${ }^{27}$ созданы отраслевые лаборатории. В 2020 г. в ГрГУ открыли филиал кафедры машиноведения и технической эксплуатации автомобилей на базе официального дилера автомобилей Geely в Гродно 28.

В 2019 г. в БГУ начал работу первый в Беларуси инновационный центр SAP Next-Gen Lab, деятельность которого направлена на решение практических задач студентами и характеризуется междисциплинарной направленностью ${ }^{29}$.

Субъекты инновационной инфраструктуры вузов ориентированы на поддержку научной и инновационной деятельности своих студентов и сотрудников с учетом особенностей и специфики учреждения образования на разных стадиях инновационного процесса. При этом каждое из таких подразделений имеет свои особенности и функции, их разнообразие в рамках одного вуза не излишне, а наоборот, обес-

${ }^{25}$ URL: https://www.belstu.by/Portals/0/www-belta-byinterview-view-razvitie-universitetov-v-sovershenstvovanii-ihinnovatsionnoj-dejatelnosti-6666.pdf

${ }^{26}$ URL: https://www.bsuir.by/ru/universitet-3-0

${ }^{27}$ URL: http://bseu.by/russian/news/201901040.htm

28 URL: https://www.grsu.by/component/k2/item/ 32670 -filial-kafedry-mashinovedeniya-i-tekhnicheskojekspluatatsii-avtomobilej-otkryli-na-baze-ooo-alfortofitsialnogo-dilera-avtomobilej-geely-v-grodno-6-fevralya.html 29 О состоянии и перспективах развития науки в Республике Беларусь по итогам 2019 года: аналитический доклад. 2020. Минск: ГУ «БелИСА». печивает синергетический эффект. Однако не в каждом университете, участвующем в Проекте, представлены все виды инновационных субъектов. Например, из 7 вузов только в одном создан центр трансфера технологий (Марахина, 2020).

Рассматривая развитие предпринимательства в вузах, нельзя не отметить и стартап-мероприятия: школы, митапы, конкурсы и др., ежегодно организуемые учреждениями образования, организациями, субъектами инновационной инфраструктуры ${ }^{30}$. Каждый год в вузах Министерства образования для студентов и молодых ученых проводятся конкурсы стартап-проектов: «Лучший молодежный проект БГУ», Конкурс стартап-проектов БНТУ, конкурс бизнес-идей и проектов «Маркет идей» и конкурс научного слэма Falling walls (БГЭУ), конкурс проектов в рамках Белорусско-китайского молодежного инновационного форума «Новые горизонты»; бизнес-бой «Лучший молодежный инновационный проект» в рамках Форума проектов программ Союзного государства (РИУП «Научно-технологический парк БНТУ "Политехник” ) и др. ${ }^{31}$

Таким образом, следует отметить, что предлагаемые в рамках Проекта меры направлены, в первую очередь, на обучение студентов предпринимательству и создание стартапов магистрантами, а также на формирование предпринимательской инфраструктуры и активизацию взаимодействия с бизнесом.

Сопоставление реализуемых мер по преобразованию белорусских вузов с изложенными выше теоретическими и методическими основами перехода к модели «Университет $3.0 »$, а также анализ процесса реализации Проекта указывают на необходимость дополнить их следующими рекомендациями.

1. Приведенные выше мероприятия носят ярко выраженный характер и создадут точки роста Университета 3.0. В то же время процесс перехода к Университету 3.0 комплексный и является не просто добавлением

30 URL: https://www.economy.gov.by/ru/plan_startap-ru

31 О состоянии и перспективах развития науки в Республике Беларусь по итогам 2019 года: аналитический доклад. 2020. Минск: ГУ «БелИСА». 
Теоретические и методические основы перехода белорусских вузов к модели «Университет 3.0»

нового элемента, а изменением принципов работы, структуры вуза в целом, как было указано выше в теоретических основах концепции «Университет 3.0». Так, например, Г.Н. Константинов, С.Р. Филонович (2007) отмечают, что «деление на кафедры, определение нагрузки преподавателей и распределение финансирования - все это проблемы, с которыми немедленно столкнутся инноваторы, пытающиеся воплотить на практике идею университета как универсума знаний. В России такой подход осложнен также жесткой системой стандартов высшего профессионального образования». Поэтому наряду с предложенными в рамках Проекта мерами внимание должно быть уделено таким направлениям, как развитие организационной структуры и культуры, активизация сотрудничества и взаимодействия с внешними субъектами, диверсификация финансирования и др.

2. Большое внимание в белорусских университетах должно быть уделено развитию науки с ориентацией на междисциплинарность, сотрудничество с производством, коммерциализацию. Важно вовлечение в научные исследования максимального числа преподавателей и других сотрудников, учащихся.

3. Следует отметить, что в настоящее время работа белорусских вузов характеризуется сильной зависимостью от государства и их переход к модели «Университет 3.0» определяется не только собственной инициативой, но и влиянием внешних факторов, в первую очередь - государственной поддержкой. Необходимо законодательно обеспечить возможность создания: фондов целевого капитала, формируемых за счет благотворительных пожертвований; спин-офф компаний в рамках университета (некоммерческой организации) и др. Важно рассмотреть возможность изменения системы финансирования университетов перехода от прямой поддержки из бюджета к косвенной - посредством целевых грантов и заказов.

4. Необходимо помнить о недопустимости простого копирования имеющихся примеров успешных зарубежных вузов. При переходе к модели «Университет 3.0» должны быть учтены особенности белорусского менталитета, традиции в сфере выс- шего образования, уровень социально-экономического развития, отраслевая структура экономики, преобладающие формы собственности, степень рыночных преобразований и др. (Бондарь, Лис, Слиж, 2018).

5. Наряду с развитием вузов важна поддержка инициатив создания Университетов 3.0 практиками. Так, например, в 2019 г. активно обсуждалась возможность появления ИТ-университета на базе парка высоких технологий, воплощающего ряд принципов предпринимательского университета.

6. Процесс перехода к модели «Университет 3.0» необходимо сделать более открытым и прозрачным. Внимание должно быть уделено обеспечению статистической отчетности и ее доступности для анализа и предложений. Необходимо информирование о проводимой и планируемой работе в рамках Проекта для популяризации подхода Университет 3.0 и обеспечения максимальной реализации результатов Проекта, вовлечения в него сотрудников вузов, обучающихся и общественности.

7. Важно активизировать развитие инновационной инфраструктуры университетов с учетом следующих направлений (Марахина, 2020): формирование в каждом вузе разнообразия субъектов инновационной инфраструктуры, поддержка их развития; активное информирование об их работе как внутри вуза, так и за его пределами; ориентация на реализацию интеллектуального потенциала максимального числа сотрудников и обучающихся, привлечение их к научной и инновационной деятельности; развитие вузовской системы научной и технической информации; обеспечение преемственности и взаимодействия субъектов инновационной инфраструктуры, а также подразделений вуза (отдел маркетинга, бухгалтерия, библиотека, аспирантура и др.).

Наряду с глобальными вызовами времени, определяющими переход к модели «Университет 3.0», вузы Республики Беларусь решают задачи роста их конкурентоспособности в условиях сужающегося внутреннего рынка, повышения инноваци- 
онной активности страны, снижения зависимости от бюджетного финансирования, реализации интеллектуального и научного потенциала.

Анализ работ, посвященных исследуемой тематике, показал: включение новой функции - предпринимательства в рамках преобразования в соответствии с моделью «Университет 3.0» значительно изменяет характер и двух других функций - образовательной и научной, а также подходов к управлению университетом. Поэтому переход к такой новой модели определяет кардинальное изменение работы университета и требует формирования новых целей, структур и среды в них (организационной культуры и мотивации), а также подходов к осуществлению деятельности и взаимодействию с окружающей средой.

В то же время меры, содержащиеся в законодательных документах и рассмотренные автором, направлены в первую очередь на развитие инфраструктуры и подготовку предпринимателей и носят, скорее, точечный, локальный характер. Поэтому важным видится их расширение и включение изменений, охватывающих работу университета в целом, - его организационную структуру, систему мотивации. Со стороны государства должна быть проделана работа, стимулирующая такие преобразования и позволяющая лигитимно реализовывать ряд направлений работы Университета 3.0 (например, создание спин-офф организаций, фондов спонсорской помощи и др.). Разработке комплекса таких мероприятий будет посвящено дальнейшее исследование.

\section{СПИСОК ЛИТЕРАТУРЫ (REFERENCES)}

Андрюшкевич О.А., Денисова И.М. 2014. Формирование предпринимательских университетов в инновационной экономике. Экономическая наука современной России. № 3. С. 87-104. [Andryushkevich O.A., Denisova I.M. 2014. The formation of entrepreneurial universities in innovative economy. Ekonomicheskaya nauka sovremennoy Rossii. No 3. PP. 87-104. (In Russ.)]

Бондарь А.В., Лис П.А., Слиж В.А. 2018. Предпринимательский университет как точка роста экономики знаний. Белорусский экономический журнал. № 4. C. 105-122. [Bondar A.V., Lis P.A., Slizh V.A. Enterpreneurial university as a growth point of knowledge economy. Belorusskiy ekonomicheskiy zhurnal. No 4. PP. 105-122. (In Russ.)]

Виссема Й.Г. 2016. Университет третьего поколения: управление университетом в переходный период. Москва: Олимп-Бизнес. 422 с. [Wissema J.G. 2016. Towards the third generation university: managing the university in transition. Moscow: Olimp-Biznes. 422 p. (In Russ.)]

Карпов А. 2017. Современный университет как драйвер экономического роста: модели и миссии. Вопросы экономики. № 3. С. 58-76. [Karpov A. 2017. Modern university as an economic growth driver: models \& missions. Voprosy ekonomiki. No 3. PP. 58-76. (In Russ.)]

Кларк Б.P. 2011. Создание предпринимательских университетов: организационные направления трансформации. Москва: Издательский дом Государственного университета - Высшей школы экономики. 240 с. [Clark B.R. 2011. Creating Entrepreneurial Universities: Organizational Pathways of Transformation. Moscow: Izdatel'skiy dom Gosudarstvennogo universiteta - Vysshey shkoly ekonomiki. 240 p. (In Russ.)]

Константинов Г.Н., Филонович С.P. 2007. Что такое предпринимательский университет. Вопросы образования. № 1. C. 49-63. [Konstantinov G.N., Filonovich S.R. 2007. What is an entrepreneurial university. Voprosy obrazovaniya. No 1. PP. 49-63. (In Russ.)]

Марахина И.В. 2020. Развитие инновационной инфраструктуры вуза при переходе к модели «Университет 3.0». Наука и инноващии. № 12. С. $64-$ 69. [Marakhina I.V. 2020. Development of innovative infrastructure at transition to the Model «University 3.0». Nauka i innozatsii. No 12. PP. 64-69. (In Russ.)]

Щелкунов М.Д. 2017. Университеты нового поколения. Вестник экономики, права и сощиологии. № 1. С. 187-192. [Shchelkunov M.D. 2017. New Generation of Universities. Vestnik ekonomiki, prava i sotsiologii. No 1. PP. 187-192. (In Russ.)]

Etzkowitz H., Zhou Ch. 2018. The Triple Helix: University-Industry-Government Innovation and Entrepreneurship. London: Routledge. 342 p. 
In citation: Belorusskiy Ekonomicheskiy zhurnal. 2021. No 1. PP. 140-155.

Belarusian Economic Journal. 2021. No 1. PP. 140-155.

\title{
TRANSITION TO «UNIVERSITY 3.0» MODEL AMONG INSTITUTIONS OF HIGHER EDUCATION IN BELARUS: ITS THEORETICAL AND METHODOLOGICAL BASIS
}

\author{
Ina Marakhina ${ }^{1}$ \\ Author affiliation: ${ }^{1}$ Belarusian State University of Informatics and Radioelectronics (Minsk, Belarus). \\ Corresponding author: Ina Marakhina (ina_marahina@tut.by).
}

ABSTRACT. The article grounds the relevance of transition for Belarusian universities towards «University 3.0» model and states it as a key area for the development of educational system in the country. With intrinsic features of the model being disclosed we identified main directions for universities reforming according to the results obtained. We analyzed as well a set of measures to advance the performance of Belarusian universities based on the «University 3.0» model and came up with a number of recommendations.

KEYWORDS: university 3.0, entrepreneurial university, model, the Republic of Belarus.

JEL-code: I23, I25.

DOI: $10.46782 / 1818-4510-2021-1-140-155$

Received 4.12.2020 